\title{
Why are there Doubts about Vaccines Efficacy yet in 2018?
}

\author{
João Paulo Martins do Carmo* \\ UEG Campus Itumbiara-GO, Brazil \\ *Corresponding author: João Paulo Martins do Carmo, Universidade Estadual de Goiás, Campus Itumbiara-GO, Brazil
}

Submission: 阱:December 22, 2018; Published: 非January 11, 2019

\section{Introduction}

Despite many articles that have been already published in this Cohesive Journal of Microbiology and Infectious Disease, it is important to stress that some of them are not necessarily in agreement with the view of this editor. Especially the ones called "opinion", in which their authors expresses what they think. But even when a scientist thinks in writing, it is good tone to show some references, because if they can't reference their opinion, there might be some references in return showing disagreement or contradictions to their simplistic view. If you don't believe in vaccines, for example, you should reference which vaccine does not work and why, scientifically, so that the discussion should be open to anyone who would like to debate it. Generalizations are not scientific, not safe and do not contribute to the scientific advancement of knowledge.

Otherwise they may simply be characterized as "fake news" shareable by social media and not by scientific magazines. The scientific method has been in use for more than 2 centuries, and was proposed for the first time by René Descartes, a mathematician and phylosophist, in what I would call someone who arrived in the frontier and simultaneously the avant-garde of science: leaving the dark Middle Ages, through Renaissance, until the Enlightment of the Scientific Revolution. Of course the scientific method as we see it nowadays is not perfect and might not be applicable in some situations, but it is universally accepted by all scientists currently: you have an idea, a hypothesis, goals to pursue and demonstrate, a method to show how to test your hypothesis, results, discussion, references and publish the data, always regarding ethical issues as a way of inspecting good and bad science, especially when it comes to human beings data being shared.

Everywhere in the world the scientists accept this methodology, and if you don't follow them, at least your opinion is regarded as pseudoscience, or just guessing, which is not science. In other words, if you cannot prove your data, it is hard to tell that your peers will accept your work as valuable and publishable. We are moving towards an era where life exists as information, everyone has their number in the system we operate under. In Brazil, we have the CPF number, which could be similarly equivalent to the American SSN. I fear that there is no turning back. In other words, what you publish is registered automatically in the world wide web, which can be accessed indefinitely and immortalize you, in a certain way of view.

On the other hand, I also understand that we, as scientists, should use a language that should be close to the lay people, so that, otherwise, we would be speaking science only to scientists. What's the point of this? That's why I took the initiative, 7 years ago, of translating the book "Your Amazing Immune SystemHow it Protects Your Body" to the Brazilian Portuguese language [1], so that more lay people could have access not only to what's been taught in Science, but specifically, in Immunology, in the last years. Why not say, centuries. In order to widen this approach, I have received support from the European Federation of Immunological Societies, which paid copyrights to the Japanese Society of Immunology, from 2012 to 2019.

As results of this work, I have organized the International Day of Immunology in my hometown and University, for 3 years in a row, including 2019. I teach Clinical Immunology, Clinical Cytopathology and Hematology to Pharmacy, Medicine, Nurse, Odontology and Physical Education courses. I also often go to High and Elementary Schools to talk about how Immunology is directly related to their routine lives at school, work or home. This has a special impact when they come to study in my university. I could not do all of this work if I have not received support from my peers, and in Brazil, especially from the Brazilian Society of Immunology, of which I am a member for more than 10 years so far.

I also would like to picture a situation that I remember when I went to the Keystone Symposia on Advancing Vaccines in the era of Genomics, held for the first time in Rio de Janeiro, Brazil, in 2013. I was representing the Foundation Oswaldo Cruz, Gonzalo Moniz Research Institute (CPqgM-FIOCRUZ), from the city of Salvador-State of Bahia, Brazil, a kind of a "Brazilian National Institutes of Health". Then, we were selected to a previous course of genomic vaccines before starting the conference per se. I remember asking the keynote speaker why aren't there vaccines against protozoa and fungi, only for viruses 
and bacteria. I was expecting the answer would be directed towards a view of molecular biology, because the title of the symposia ("Advancing Vaccines in the Era of Genomics"). But he just told me it was "because the Pharmaceutical Industry has no interest on this, once they are diseases of poor countries". Although not much surprised, I felt disappointment, because this did not sounded to me as a scientific answer, but a more political one. Then I replicated to him that my scientific view is that nowadays we are too focused on molecular biology (which is taught as "the science that studies the phenomena involving DNA translation, passing through mRNA coding, to protein synthesis"). I always have troubles with this definition, because, for me, carbohydrates and lipids are also part of the so-called "molecular biology". Years later after my first contact with the "molecular biology", after the Genome Project (2003), another discipline would rise to explain this discrepancy: Epigenetics, which is not well understood in depth by the lay people yet.

In the name of Didatics, we are required to separate disciplines, which sometimes may cause distortions in the scientific knowledge. Thus, in my view, one simple difference in the nature of virus and bacteria to protozoa and fungi, which is for instance, the presence of ergosterol in their membranes, would be enough to alter the response of the human immune system against these microorganisms, once we have cholesterol. But once the vaccines against protozoa and fungi are made with "immunogenic peptides", based on the concept of MHC restriction of the immune response [2-4], scientists tend to forget (for lack of a better world to describe this phenomena) that we are infected with the whole fungus or protozoa cell, not only their "immunogenic peptides", most of which are done with the aid of the recombinant DNA technology.

To open a new avenue forward this "petide-centric" view of the immune response, from the last 10 years on, there has been an increase in the lipidomic knowledge. I would like to cite the ground breaking article of [5], in which she demonstrates for the first time antigen presenting cells (APCs) presenting human lipid antigens to T cells, which, in my opinion, will make a hole in our current established immunological knowledge that " $\mathrm{T}$ cells recognize only peptides in the context of MHC molecules in the surface of APCs or infected cells or tumor cells" [2,4], which awarded Zinkernagel and Doherty a Nobel Prize in 1996. We, as scientists, should pay more attention to what we call "molecular biology" (or other sciences) when we simplify what we think, but not forgetting that the divisions are made by Didactics only, because they are not necessarily the Nature's rules. Thus, it is not completely true that the "Pharmaceutical Industry is not interested in this diseases of poor countries", once a successful vaccine against Leishmania spp was developed, at least for Brazilian dogs so far [6]. But once they are one of the urban reservatoires, this discovery is a major breakthrough. Another argument against this view is that countries like USA, Italy and Spain (which are regarded as developed countries, compared to the African ones) have increased their incidence of leishmaniasis patients. In the case of the USA, for instance, most of their leishmaniasis patients are acquired when their soldiers are in duty in high incidence leishmaniasis countries, such as Afghanistan, thus no autochthone case was reported so far. But they do perform research on it. So, there is a genuine interest. About world spread "fake news" on vaccines, for lack of time and space, we could talk more about it in other opportunity.

\section{References}

1. Carmo JPM (2016) Your amazing immune system: How it protects your body. ( $6^{\text {th }}$ edn), Berlin, Germany.

2. Shevach E (1998) MHC restriction. In: Encyclopedia of Immunology, ( $2^{\text {nd }}$ edn), pp. 1709- 1712.

3. Zinkernagel RM, Doherty PC (1997) The discovery of MHC restriction. Immunol Today 18(1): 14-17.

4. Zinkernagel RM, Doherty PC (1979) MHC-restricted cytotoxic T cells: studies on the biological role of polymorphic major transplantation antigens determining T-cell restriction-specificity, function and responsiveness. Advances in Immunology 27: 51-177.

5. Jong DA, Cruz PV, Cheng TY, Clark RA, Rhijn VI, et al. (2010) CD1aautoreactive $\mathrm{T}$ cells are a normal component of the human $\alpha \beta \mathrm{T}$ cell repertoire. Nat Immunol 11(12): 1102-1109.

6. Fiuza JA, Gannavaram S, Santiago H, Selvapandiyan A, Souza D, et al. (2015) Vaccination using live attenuated Leishmania donovani centrin deleted parasites induces protection in dogs against Leishmania infantum. Vaccine 33(2): 280-288.

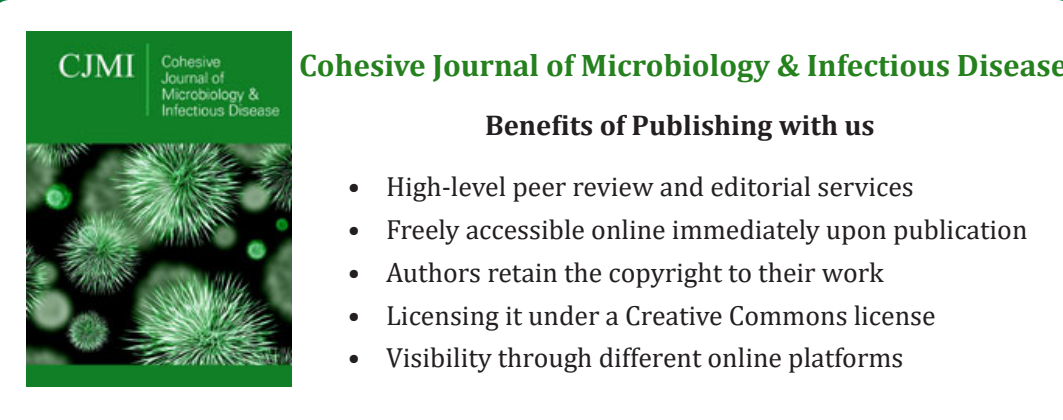

